\title{
Effect of temperature on ultrasonic velocities of unconsolidated sandstones reservoirs during the SAGD recovery process
}

\author{
D-H. Doan ${ }^{1,2, a}$, J-F. Nauroy ${ }^{1}$, P. Delage ${ }^{2}$, and M. Mainguy ${ }^{3}$ \\ ${ }^{1}$ Institut Français du Pétrole, 1-4 Av. du Bois Préau, 92852 Rueil-Malmaison Cedex, France \\ ${ }^{2}$ Ecole des Ponts ParisTech, 6-8 Av. Blaise Pascal, F-77455 Marne la Vallée Cedex 2, France \\ ${ }^{3}$ TOTAL Office EB-181 CSTJF, Av. Larribau 64018 Pau cedex, France
}

\section{Abstract}

The steam assisted gravity drainage (SAGD) is a thermal in-situ technology that has been successfully used to enhance the recovery of heavy oil and bitumen in the Western Canada and in the Eastern Venezuela basins. Pressure and temperature variations during SAGD operations induce complex changes in the mechanical and acoustic properties of the reservoir rocks as well as of the caprock. To study these changes, measurements of ultrasonic wave velocities Vp, Vs were performed on both reconstituted samples and natural samples from oil sands reservoir. Reconstituted samples were made of Fontainebleau sands with a slight cementation formed by a silicate solution. They have a high porosity (about $30 \%$ to $40 \%$ ) and a high permeability (up to $10 \mathrm{D}$ ). Natural oil sands samples are unconsolidated sandstones extracted from the fluvio-estuarine McMurray Formation in Alberta (Canada). The saturating fluids were bitumen and glycerol with a strongly temperature dependent viscosity. The tests were carried out at different temperatures (in the range $40^{\circ}$ and $+86^{\circ} \mathrm{C}$ ) and at different effective pressures (from 12 bars up to 120 bars).

Experimental results firstly showed that the elastic wave propagation velocities measured are strongly dependent on temperature and pore fluid viscosity whereas little effect of effective pressure was observed. Velocities decreased with increasing temperature and increased with increasing effective pressure. These effects are mainly due to the variations of the saturating fluids properties. Finally, the tests were modelled by using Ciz and Shapiro (2007) approach and satisfactory velocities values were obtained with highly viscous fluids, a case that cannot be easily explained by using the poro-elastic theory of Biot-Gassmann.

Keywords: steam-assisted gravity drainage SAGD, temperature, oil sand, heavy oil, bitumen, viscous fluids, mechanical and acoustic properties, ultrasonic wave velocity, Ciz and Shapiro.

\section{References}

1. R. Ciz, S.A. Shapiro, Geophysics, 72:A75-A79 (2007)

a e-mail : dinh-hong.doan@ifp.fr

This is an Open Access article distributed under the terms of the Creative Commons Attribution-Noncommercial License 3.0, which permits unrestricted use, distribution, and reproduction in any noncommercial medium, provided the original work is properly cited. 